Çukurova Üniversitesi Mühendislik Mimarlık Fakültesi Dergisi, 32(1), ss. 177-185, Mart 2017

Çukurova University Journal of the Faculty of Engineering and Architecture, 32(1), pp.177-185, March 2017

\title{
Bir Nano Adsorbent ile Reaktif Black 39 Boyar Maddesinin Distile Sudan ve Sentetik Atıksudan Giderimi
}

\author{
Behzat BALCI ${ }^{* 1}$, Fatma Elçin ERKURT ${ }^{1}$ \\ ${ }^{1}$ Çukurova Üniversitesi, Mühendislik Mimarlkk Fakültesi, Çevre Mühendisliği Bölümü, Adana \\ Geliş tarihi: 11.01.2017_ Kabul tarihi: 14.03 .2017
}

$\ddot{\mathbf{O} z}$

Bu çalışmada yüzeyi nano manyetit ile kaplanmış Eucalyptus camaldulensis kabukları (NEK), bir tekstil boyar maddesi olan Reaktif Black 39'un (RB39) distile su ve sentetik atıksudan gideriminde düşük maliyetli bir adsorbent olarak kullanılmıştır. Adsorpsiyon üzerine temas zamanı, $\mathrm{pH}$, sicaklık NEK dozu ve başlangıç boyar madde konsantrasyonu gibi çeşitli parametrelerin etkisi araştırılmıştır. Çalışmalar NEK'in adsorpsiyon kapasitesinin başlangıç boyar madde konsantrasyonunun, $\mathrm{pH}$ 'ın ve sıcaklığın artmasıyla arttığını, NEK dozunun artmasıyla azaldığını göstermiştir. 300 mg/L RB39'un 150 mL distile sudan yaklaşık \%94 verimle giderilmesi için $0,2 \mathrm{~g}$ NEK yeterli olduğu tespit edilmiştir. Diğer taraftan 300 mg/L RB39'un sentetik atıksudan yaklaşı \%92 verimle giderilmesi için 0,4 g NEK'in yeterli olduğu bulunmuştur. Freundlich izotermi $\left(\mathrm{R}^{2}=0,993\right)$ adsorpsiyon sürecini Langmuir izotermine göre daha etkili bir şekilde açıklamıştır. Langmuir izotermi NEK'in maksimum adsorpsiyon kapasitesini 432,12 mg/g olarak tahmin etmiştir.

Anahtar Kelimeler: Adsorpsiyon, Eucalyptus camaldulensis, Manyetit

\section{Removal of Reactive Black 39 Dye from Distilled Water and Synthetic Wastewater by a Nano Adsorbent}

\begin{abstract}
In the present study, nano magnetite coated Eucalyptus camaldulensis barks (NEC) was used as a lowcost adsorbent for the removal of a textile dye Reactive Black 39 (RB39) from distilled water and synthetic wastewater. The effects of the various parameters, contact time, $\mathrm{pH}$, temperature, NEC dosage and initial dye concentration on the adsorption were investigated. It was found that the adsorption capacity of NEC increases by increasing the RB39 concentration, $\mathrm{pH}$ and temperature and by decreasing the dosage of NEC. $0.2 \mathrm{~g}$ NEC was found to be sufficient for the removal of $300 \mathrm{mg} / \mathrm{L} \mathrm{RB} 39$ from $150 \mathrm{~mL}$ distilled water with $\sim 94 \%$ removal efficiency. On the other hand $0.4 \mathrm{~g}$ NEC was found sufficient for the removal of RB39 from synthetic wastewater with $\sim 92 \%$ removal efficiency. The Freundlich isotherm model described the adsorption process more effectively $\left(R^{2}=0.993\right)$ than the Langmuir isotherm model. The Langmuir isotherm predicted a $432.12 \mathrm{mg} / \mathrm{g}$ maximum adsorption capacity of NEC.
\end{abstract}

Keywords: Adsorption, Eucalyptus camaldulensis, Magnetite

*Sorumlu yazar (Corresponding author): Behzat BALCI, behzatbalci@gmail.com 


\section{GíRiş}

Boyar madde içeren atıksular, oluşturacağı ekolojik problemlerden dolayı özel önem verilmesi gereken kirleticiler arasına girmektedir. Dünya genelinde 10.000 tip farklı boya ve ortalama 700.000 ton miktarında boya kullanımı mevcuttur. Boyar maddelerin sucul ortamlarda toksik, kanserojenik ve estetik problemlere neden olduğu bilinmektedir [1]. Reaktif boyar maddeler parlak yapıları, hızlı uygulanabilirliği ve düşük maliyetinden dolayı tekstil endüstrisinde en yaygın kullanılan boyar madde tipidir [2]. Reaktif boyar maddeler suda çok iyi çözünebilir ve azoik yapılarından dolayı biyolojik parçalanmaya karşı oldukça dirençlidirler. Geleneksel arıtma süreçleri sonucunda, çıkış sularında reaktif boyar madde kalıntıları mevcut olabilmektedir [3]. Adsorpsiyon süreci, boyar maddeler gibi çözünmüş organik kirleticilerin sudan gideriminde yüksek kaliteli çıkış suyu sağladığından dolayı ön plana çıkmaktadır [4].

Manyetik ayırma teknolojisi, etkili ve hızlı sonuç veren bir teknoloji olmasından dolayı son yıllarda bilim adamlarının önemle dikkatini çekmiştir. $\mathrm{Bu}$ teknoloji, ilaç, hücre biyolojisi, analitik kimya, madencilik ve çevre teknolojisi gibi pek çok alanda kullanım göstermektedir [5]. Bu teknolojinin en önemli avantajları; büyük miktarlarda atıksuyu kısa sürelerde arıtabilmesi ve yeni kirletici üretmemesidir [6]. Manyetik ayırma teknolojisinin adsorpsiyon süreci ile birlikte kullanılması çevresel uygulamalarda geniş yer tutmaktadır. Manyetit nano partiküller $\left(\mathrm{Fe}_{3} \mathrm{O}_{4}\right)$ adsorpsiyon süreçlerinde, adsorbentin yüzey alanını arttırmak için bir yüzey kaplayıcı olarak kullanılabilmektedir. Manyetit ile kaplanmış bu nano adsorbentler, artan yüzey alanlarına ve yüksek derecede aktif adsorpsiyon sitlerine sahip olmasından dolayı adsorpsiyon süreçlerinde son yıllarda ilginin odağı haline gelmiştir [7].

Literatürde boyar maddelerin çeşitli adsorbentler ile giderimi üzerine dayalı olan çalışmalar, genel olarak distile sudan boyar madde giderimi üzerine yoğunlaşmıştır [8-15]. Bu çalışmalarda distile suda, boyar madde haricinde kirleticiler bulunmamaktadır. Böylece adsorpsiyon mekanizmaları sadece boyar madde ile adsorbent arasında gerçekleşmektedir. Hiç şüphesiz; boyar madde ile adsobent arasındaki özellikli sorpsiyon etkileşimlerini anlamak adına, distile su ortamindan boyar madde giderimi önem arz etmektedir. Ancak bunun yanında, boyar maddelerin bulunduğu atıksular boyar maddeler dışında alkalinite, asidite, $\mathrm{NH}_{4}-\mathrm{N}, \mathrm{Cl}^{-}$iyonları, askıda katı maddeler ve yağ gres gibi kirleticiler içermektedir [16,17]. Bu kirleticiler, adsorbent yüzeyindeki adsorpsiyon sitlerini işgal ederek, oluşturabileceği rekabetçi adsorpsiyon ile atıksudan boyar madde giderim verimlerini düşürebilmektedir. $\mathrm{Bu}$ durumda distile sudan boyar madde giderimi ile atısudan boyar madde giderimi süreçleri arasında, giderim verimleri açısından önemli farklar ortaya çıkabilmektedir.

$\mathrm{Bu}$ çalışmanın amacı, Eucalyptus camaldulensis kabuklarının yüzeyinin manyetit ile kaplanmasıyla elde edilmiş olan düşük maliyetli bir nano adsorbent ile Reaktif Black 39 (RB39) boyar maddesinin distile sudan ve sentetik olarak oluşturulmuş tekstil atıksuyundan, değişen parametreler altında, adsorpsiyonla gideriminin araştırılmasıdır. Eucalyptus camaldulensis kabukları yenilenebilir, ekonomik ve bol bulunan bir materyal olmasından dolayı nano adsorbent üretiminde tercih edilmiştir.

\section{MATERYAL VE METOT}

\subsection{NEK EIdesi}

Eucalyptus camaldulensis kabukları, Çukurova Üniversitesi Balcalı kampüsünden toplanmıştır. Toplanan kabuklar, kir ve tozdan temizlenmek üzere, sıcak su ile yıkanıp $70^{\circ} \mathrm{C}$ 'de 24 saat kurutulmuştur. Kurutulan kabuklar parçalanıp ortalama 0,2 mm dane çapında olacak şekilde elek analizine tabii tutulmuştur. NEK, kimyasal çöktürme metoduna göre elde edilmiştir. 12,5 g kabuk, $1,455 \mathrm{~g} \mathrm{FeCl}_{3} \cdot 6 \mathrm{H}_{2} \mathrm{O}$ ve $7,5 \mathrm{~g} \mathrm{FeSO}_{4} \cdot 7 \mathrm{H}_{2} \mathrm{O}$ içeren $1000 \mathrm{~mL}$ çözeltiye eklenmiştir. Süspanse 
karışım $50^{\circ} \mathrm{C}^{\prime}$ ye kadar isıtılıp bu sıcaklıkta azot gazı akımı altında 2 saat boyunca karıştırılmıştır. Karışımın pH'1 10'a gelinceye kadar damla damla $\mathrm{NaOH}$ çözeltisi eklenip, 5 saat boyunca $80^{\circ} \mathrm{C}$ 'de sabit tutularak güçlü bir şekilde karıştırılmıştır. İşlem sonunda, NEK oksijensiz distile su ile yıkanıp $80^{\circ} \mathrm{C}$ 'de 24 saat kurutulmuştur. Muhtemel $\mathrm{Fe}_{3} \mathrm{O}_{4}$ oluşumu eşitlik 1'de verilmiştir.

$\mathrm{Fe}^{+2}+2 \mathrm{Fe}^{+3}+8 \mathrm{OH}^{-} \rightarrow \mathrm{Fe}_{3} \mathrm{O}_{4}+4 \mathrm{H}_{2} \mathrm{O}$

\subsection{Boyar Madde ve Ölçümü}

RB39 boyar maddesi, (CAS No: 68259-02-9) Adana'da yerel bir tekstil firmasından temin edilmiştir. Sıvı fazdaki kalıntı boyar madde konsantrasyonunun tespiti, spektrofotometrede (Chebios Opitimum-one) $531 \mathrm{~nm}$ dalga boyunda hazırlanmış olan kalibrasyon eğrisi üzerinden numunelerin okutulmasıyla gerçekleştirilmiştir.

\subsection{Adsorpsiyon Çalışmaları}

RB39'un NEK tarafindan adsorpsiyonla giderilmesi süreci üzerine, temas zamanının $(5,10$, $15,20,30,40,50 \mathrm{dk})$, pH'in $(2,3,4,5,6,7,8,9$ ve 10), sicaklığın $(15,20,25,30,35,40,45$, $\left.50{ }^{\circ} \mathrm{C}\right)$, NEK dozunun $(0,1,0,2,0,3$ ve $0,4 \mathrm{~g})$ ve başlangıç RB39 konsantrasyonunun $(75,100,150$, 200 ve $300 \mathrm{mg} / \mathrm{L})$ etkisi araştırılmıştır. Boyar madde giderimi distile sudan ve sentetik atıksudan olmak üzere iki kısımda gerçekleştirilmiştir. Boyar maddenin eklendiği sentetik atıksu kompozisyonu $6 \mathrm{mg} / \mathrm{L} \mathrm{NH}_{4}-\mathrm{N}, 160 \mathrm{mg} / \mathrm{L}$ yağ gres ve $18000 \mathrm{mg} / \mathrm{L}$ $\mathrm{Cl}^{-}$içerecek şekilde hazırlanmıştır [16,17]. Yapılan adsorpsiyon çalışması kesikli süreç olup, $500 \mathrm{~mL}$ erlenmayerlerde ve $150 \mathrm{~mL}$ hacminde sulu çözeltide gerçekleştirilmiştir. Karıştırma işlemi 250 rpm'de, sıcaklık ayarlı çalkalayıcı ile sağlanmıştır. Deneyler üç tekrarlı yapılmış olup, hesaplamalarda ortalama değerler kullanılmıştır.

\section{BULGULAR VE TARTIŞMA}

\subsection{Temas Zamanının Etkisi}

Adsorpsiyon bir denge tepkimesine benzer ve çözeltide kalan çözünen derişimi ile yüzeye tutulan çözünen derişimi arasında dinamik bir dengeye ulaşıncaya kadar devam eder. Dengenin, çözünenin katı ve sıvı fazları arasında belirli bir dağılımı vardır. Dağılım oranı, adsorpsiyon işleminde denge durumunun bir ölçüsüdür. Adsorpsiyon dengesini belirtmek için sabit sıcaklıkta, denge zamanında, çözeltide kalan çözünen derişimine karşı, katı adsorbentin birim ağırlığında adsorbe edilen çözünen miktarı grafiğe geçirilir [18].

Denge zamanındaki adsorbentin birim ağırlığında (g) adsorbe edilen çözünen miktarı (mg) olan " $\mathrm{q}_{\mathrm{e}}$ " değerini tespit etmek gerekmektedir. Aslında " $\mathrm{q}_{\mathrm{e}}$ " değerinin tam olarak elde edilmesi oldukça zordur. Bunun nedeni, pek çok adsorpsiyon sürecinde, adsorbat ile adsorbent arasındaki etkileşimin, ilk hızlı tepkimeden sonra oldukça yavaş cereyan etmesidir. Bu durum, denge zamanına kesin olarak ulaşılıp ulaşılmadığını anlamayı zorlaştırır. Bu gibi durumlarda en yaklaşık bir " $\mathrm{q}_{\mathrm{e}}$ " değeri seçilir. Seçilen en yaklaşık " $\mathrm{q}_{\mathrm{e}}$ " değerine ait denge zamanından sonraki zamanlardaki " $\mathrm{q}_{\mathrm{t}}$ " değerleri en yaklaşık q değerine oldukça yakındır [19].

Adsorpsiyon denge zamanı çalışması, distile sudan ve sentetik atıksudan $300 \mathrm{mg} / \mathrm{L}$ boyar madde için pH 7'de, $20{ }^{\circ} \mathrm{C}$ 'de ve 0,1 gram NEK dozu ile gerçekleştirilmiştir. Yapılan çalışmada adsorpsiyon denge zamanının distile su ve sentetik atıksu için $40 \mathrm{dk}$ olduğu tespit edilmiştir. Distile su için ve sentetik atıksu için denge zamanında hesaplanan adsorpsiyon kapasiteleri sirasiyla 185,25 ve 133,20 $\mathrm{mg} / \mathrm{g}$ olarak hesaplanmıştır. Sentetik atıksuda daha düşük adsorpsiyon kapasitesi elde edilmesinin nedeni, boyar madde dışında sentetik atıksuya eklenmiş olan diğer kirleticilerin NEK'in adsorpsiyon sitlerini belli oranda işgal ederek boyar madde giderimini negatif yönde etkilemesinden olduğu düşünülmektedir. Adsorpsiyon kapasitesi (q) Eşitlik 2 kullanılarak hesaplanmıştır. Adsorpsiyon denge grafiği Şekil 1'de verilmiştir.

$q=\frac{\left(C_{0}-C_{e}\right)}{W} V$ 
$\mathrm{q}=$ Adsorpsiyon kapasitesi, $\mathrm{mg} / \mathrm{g}$

$\mathrm{C}_{0}=$ Başlangıç boyar madde konsantrasyonu, $\mathrm{mg} / \mathrm{L}$

$\mathrm{C}_{\mathrm{e}}=$ Çıkış boyar madde konsantrasyonu, $\mathrm{mg} / \mathrm{L}$

$\mathrm{V}=$ Çözelti hacmi, L

$\mathrm{W}=$ Adsorbent kütlesi, $\mathrm{g}$

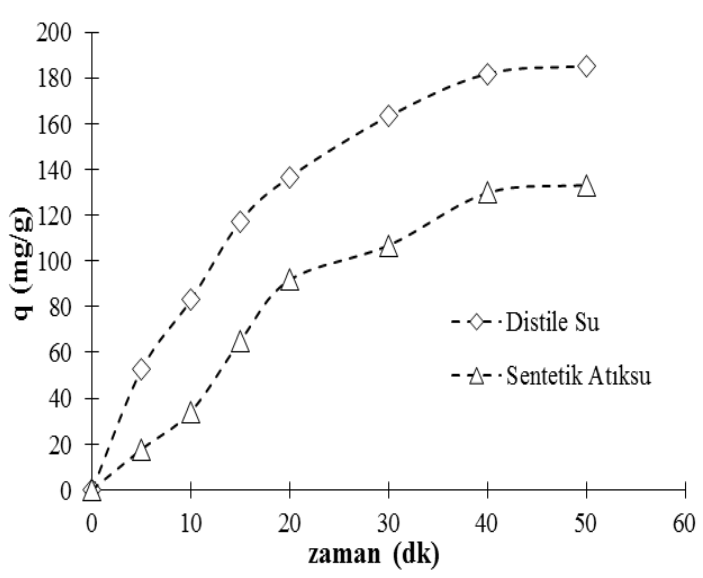

Şekil 1. Adsorpsiyon denge zamanı

\section{2. pH'ın Adsorpsiyon Sürecine Etkisi}

pH'ın adsorpsiyon süreci üzerine olan etkisinin araştırılması, $300 \mathrm{mg} / \mathrm{L}$ boyar madde için, $20^{\circ} \mathrm{C}$ 'de ve 0,1 gram NEK dozu ile gerçekleştirilmiştir. Adsorpsiyon süreçlerinde, $\mathrm{pH}$ değeri adsorpsiyon sürecini etkileyebilecek en önemli parametrelerden biridir. Çözeltinin pH'1, adsorbent yüzey yük yoğunluğunu ve çözünmüş iyon konsantrasyonunu değiştirebileceğinden, adsorpsiyon kapasitesi üzerine etki eder [20]. NEK'in distile sudan ve sentetik atıksudan RB39 gideriminde $\mathrm{pH}$ etkisini gösteren grafik, Şekil 2'te verilmiştir. Asidik koşullarda adsorpsiyon kapasitesinin, bazik koşullara göre önemli ölçüde düştüğü görülmüştür. Düşük pH değerlerindeki düşük adsorpsiyon kapasitesinin, $\mathrm{H}^{+}$iyonlarının adsorbent yüzeyini işgal etmesi ve RB39 tutulumunu azaltmasından olabileceği düşünülmektedir [21]. pH 2'de, distile su ve sentetik atıksu için adsorpsiyon kapasiteleri sirasiyla 53,25 ve 19,05 mg/g bulunurken, $\mathrm{pH}$ 9'da 269,55 ve $200,10 \mathrm{mg} / \mathrm{g}$ olarak bulunmuştur. En yüksek adsorpsiyon kapasiteleri pH 10 için tespit edilirken pH 10 ile 9'daki adsorpsiyon kapasiteleri arasındaki fark önemli olmadığından optimum $\mathrm{pH}$ değeri olarak 9 seçilmiş ve sonraki çalışmalar bu $\mathrm{pH}$ değerinde gerçekleştirilmiştir. Tüm $\mathrm{pH}$ değerlerinde denge zamanının yaklaşık 40 dakika civarı olduğu tespit edilmiştir.

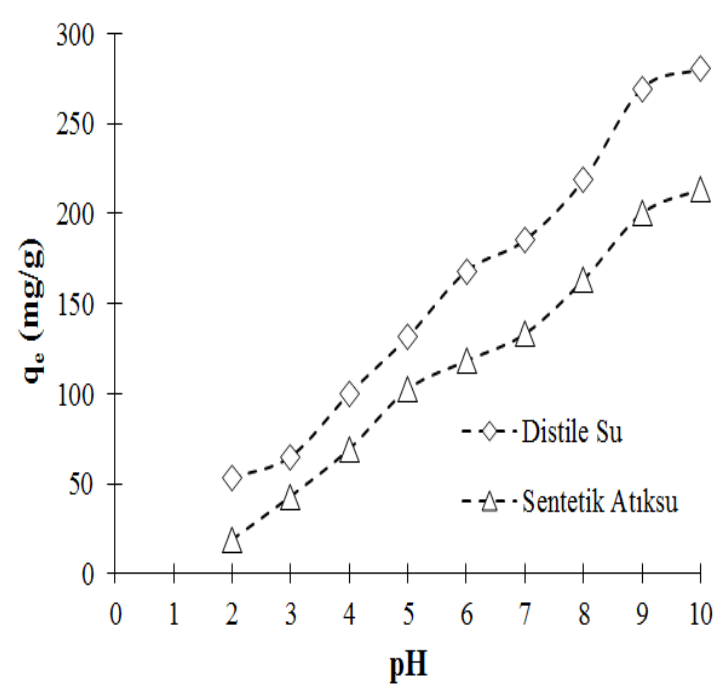

Şekil 2. Adsorpsiyon süreci üzerine pH'in etkisi

\subsection{Adsorpsiyon Süreci Üzerine Sıcaklığın Etkisi}

Adsorpsiyon sürecine sicaklığın etkisinin araştırıldığı deneysel süreç, $300 \mathrm{mg} / \mathrm{L}$ boyar madde için, $\mathrm{pH}$ 9'da ve 0,1 gram NEK dozu ile gerçekleştirilmiştir. Yapılan çalışmalar, NEK adsorpsiyon kapasitesinin sicaklığın artmasıyla önemli derecede arttığını göstermiştir. Adsorpsiyon kapasitesi $15^{\circ} \mathrm{C}$ 'de distile su ve sentetik atıksu için sırasıyla 231,60 mg/g ve $161,25 \mathrm{mg} / \mathrm{g}$ olarak hesaplanırken, $50^{\circ} \mathrm{C}$ 'de yine distile su ve sentetik atıksu için sırasıyla 407,10 ve $351,60 \mathrm{mg} / \mathrm{g}$ olarak hesaplanmıştır. Yüksek sıcaklıklarda yüksek adsorpsiyon kapasitesinin elde edilmesinin, sıcaklık artışıyla RB39 moleküllerinin mobilitesinin ve NEK aktif sitlerinin artmasına dayalı olabileceği düşünülmektedir [22]. Adsorpsiyon sürecine sıcaklığın etkisini gösteren grafik, Şekil 3'te verilmiştir. $50^{\circ} \mathrm{C}$ optimum sicaklık olarak seçilmiş ve bundan sonraki çalışmalar bu sıcaklıkta gerçekleştirilmiştir. 


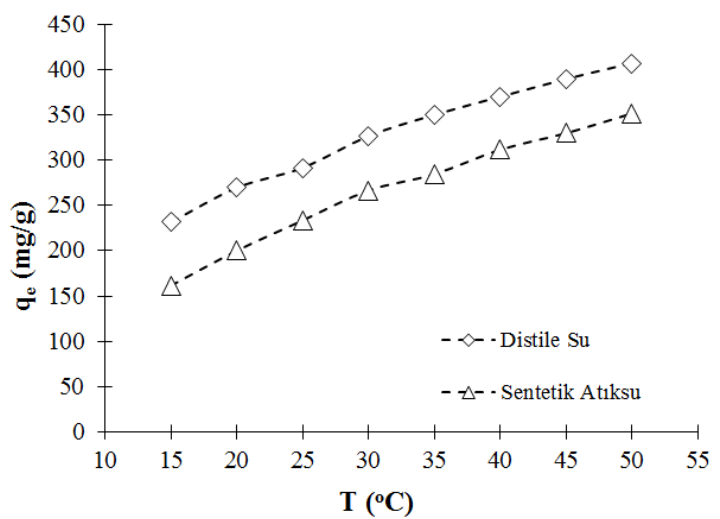

Şekil 3. Adsorpsiyon süreci üzerine sicaklığın etkisi

\subsubsection{Termodinamik Parametreler}

Standart Gibbs serbest enerji $\left(\Delta \mathrm{G}^{\circ}\right)$, entalpi $\left(\Delta \mathrm{H}^{\circ}\right)$ ve entropi $\left(\Delta \mathrm{S}^{\circ}\right)$ gibi termodinamik parametreler, Eşitlik 3 ve 4 kullanılarak hesaplanmıştır. Termodinamik parametrelerin hesaplanmasında, farklı sicaklıklarda distile sudan RB39 giderimi üzerine yapılan deneysel süreçten elde edilen veri kullanılmıştır.

$$
\begin{aligned}
& \Delta G^{0}=\Delta H^{0}-\Delta S^{0} \\
& \log \left(\frac{q_{e}}{C_{e}}\right)=\frac{\Delta S^{0}}{2,303 R}+\frac{-\Delta H^{0}}{2.303 R T}
\end{aligned}
$$

$\Delta H^{\circ}$ ve $\Delta S^{\circ} \log \left(q_{e} / C_{e}\right)$ 'nin $1 / T^{\prime}$ ye karşı grafiğe geçirilmesi ile elde edilen doğrunun eğimi ve kesim noktasından hesaplanır. Burada $\mathrm{q}_{\mathrm{e}}$ denge zamanındaki adsorpsiyon kapasitesini $(\mathrm{mg} / \mathrm{g}), \mathrm{C}_{\mathrm{e}}$ denge zamanında sıvı fazdaki kalıntı boyar madde konsantrasyonunu (mg/L), T sicaklığ $(\mathrm{K})$ ve R gaz sabitini (8,314 J/mol.K) ifade eder [23]. Termodinamik parametrelerin hesaplanmasinda kullanılan grafik ve doğru denklemi Şekil 4'de, termodinamik parametreler ise Çizelge 1 'de verilmiştir.

Gibbs serbest enerjisi, adsorpsiyon sürecinin spontanite seviyesini ifade eder. Yüksek negatif Gibbs değerleri, enerji açısından daha elverişli bir adsorpsiyon sürecinin olduğunu gösterir [24]. Tüm sıcaklık değerlerinde $\Delta G^{\circ}$ değerlerinin negatif çıkması, bu sıcaklıklarda adsorpsiyon sürecinin spontanitesinin elverişli olduğunu işaret etmektedir.

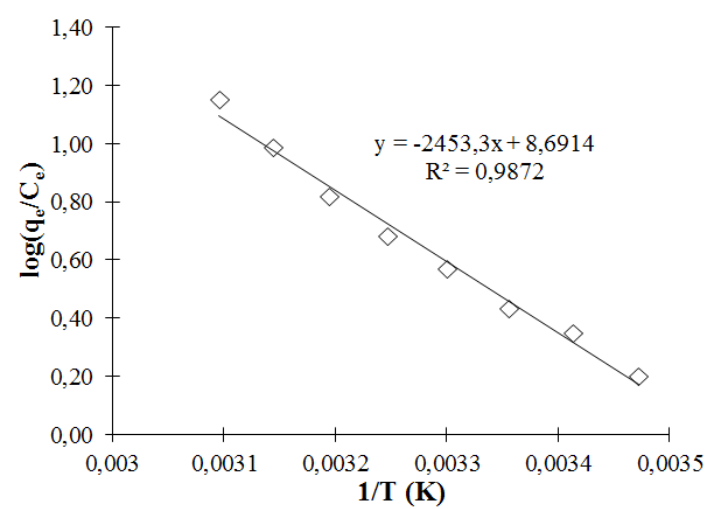

Şekil 4. $\log \left(q_{e} / C_{e}\right)$ 'nin $1 / T^{\prime}$ ye karşı grafiğe geçirilmesi

\begin{tabular}{|c|c|c|c|}
\hline $\begin{array}{c}\text { Sicaklık } \\
{ }^{\circ} \mathrm{C}\end{array}$ & $\begin{array}{c}\Delta G^{\circ} \\
\mathrm{kj} / \mathrm{mol}\end{array}$ & $\begin{array}{c}\Delta H^{\circ} \\
\mathrm{kj} / \mathrm{mol}\end{array}$ & $\begin{array}{c}\Delta S^{\circ} \\
\mathrm{kj} / \mathrm{mol}\end{array}$ \\
\hline 15 & $-953,84$ & \multirow{8}{*}{46973,68} & \multirow{8}{*}{166,415} \\
\hline 20 & $-1785,915$ & & \\
\hline 25 & $-2617,99$ & & \\
\hline 30 & $-3450,065$ & & \\
\hline 35 & $-4282,14$ & & \\
\hline 40 & $-5114,215$ & & \\
\hline 45 & $-5946,29$ & & \\
\hline 50 & $-6778,365$ & & \\
\hline
\end{tabular}

Çizelge 1. Termodinamik parametreler

Pozitif $\Delta \mathrm{H}^{\circ}$ değeri RB39'un NEK üzerine adsorpsiyonunun endotermik bir süreç olduğunu göstermektedir. Pozitif $\Delta \mathrm{S}^{\circ}$ değeri adsorpsiyon sırasında katı-sıv1 ara yüzeyindeki rastgeleliğin arttığını göstermektedir [25].

\subsection{Adsorpsiyon Süreci Üzerine NEK Dozunun Etkisi}

NEK doz çalışmaları, $300 \mathrm{mg} / \mathrm{L}$ RB39 için $50^{\circ} \mathrm{C}^{\prime} \mathrm{de}, \mathrm{pH}$ 9'da gerçekleştirilmiştir. Yapılan çalışmalar, NEK dozunun artmasıyla adsorpsiyon kapasitesinin azaldığını, boyar madde giderim veriminin ise arttığını göstermiștir. 0,1 gram NEK 
için distile su ve sentetik atıksuda adsorpsiyon kapasitesi surasıly 407,10 ve $351,60 \mathrm{mg} / \mathrm{g}$ bulunurken, 0,4 gram NEK için sırasıyla 112,08 ve $102,90 \mathrm{mg} / \mathrm{g}$ olarak tespit edilmiştir. Adsorpsiyon kapasitesinin NEK dozunun artmasiyla azalmasi; RB39'un NEK yüzeyi ve sıvı çözelti arasındaki konsantrasyon gradyanına bağlı olan bir durumdur [25]. 0,4 gram NEK ile RB39 distile sudan \%99,6 verimle giderilirken, sentetik atısudan \%91,4 verimle giderilmiştir. Adsorpsiyon süreci üzerine NEK dozunun etkisini gösteren grafik, Şekil 5'te verilmiştir.

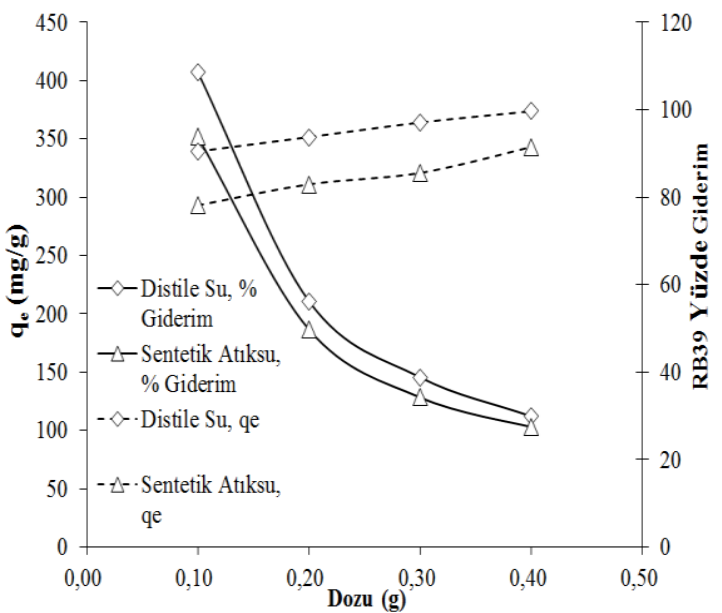

Şekil 5. Adsorpsiyon süreci üzerine NEK dozu etkisi

\subsection{Adsorpsiyon Süreci Üzerine Konsantrasyonunun Etkisi}

Adsorpsiyon süreci üzerine RB39 konsantrasyonunun etkisini görmek için yapılan deneysel çalışma; $50^{\circ} \mathrm{C}^{\prime} \mathrm{de}, \mathrm{pH} 9$ 'da ve $0,1 \mathrm{~g}$ NEK dozu ile gerçekleştirilmiştir. Yapılan çalışmalar, adsorpsiyon kapasitesinin, RB39 konsantrasyonunun artmasıyla arttığını ve RB39 konsantrasyonunun azalmasıyla azaldığını göstermiş̧tir. Distile suda adsorpsiyon kapasiteleri 75 ve $300 \mathrm{mg} / \mathrm{L}$ boyar madde konsantrasyonları için sırasıyla; 110,92 ve $407,10 \mathrm{mg} / \mathrm{g}$ bulunmuştur. Sentetik attksuda adsorpsiyon kapasiteleri ise 75 ve $300 \mathrm{mg} / \mathrm{L}$ boyar madde konsantrasyonları için sırasıyla; 92,25 ve $351,50 \mathrm{mg} / \mathrm{g}$ bulunmuştur. RB39 konsantrasyonunun etkisini gösteren grafik, Şekil 6'da verilmiştir.

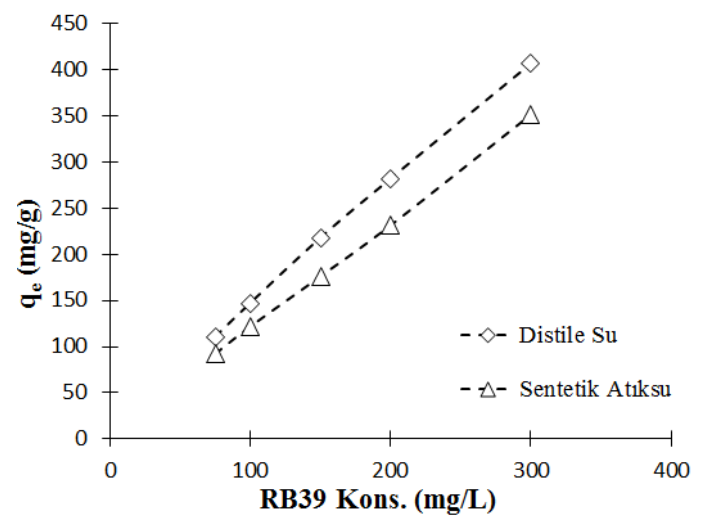

Şekil 6. Adsorpsiyon süreci üzerine RB39 konsantrasyonunun etkisi

\subsection{Adsorpsiyon İzotermleri}

Adsorpsiyon izotermleri, adsorpsiyonun denge zamanına ulaştığında, adsorplanan moleküllerin katı ve sıvı faz arasında nasıl bir dağılım sergilediğini gösterir. Adsorpsiyon sürecinden elde edilen veri ile en iyi izoterm modellerinin elde edilmesi, adsorpsiyon süreçlerinin tasarımı için önemli bir adımdır [26]. Distile sudan farklı konsantrasyonlarda boyar madde gideriminin araştırılmasından elde edilen veri Langmuir ve Freundlich izotermleri ile test edilmiştir. İzoterm parametreleri non-lineer yöntem ile kalıntı karelerin toplamının minimizasyonu metodu kullanılarak hesaplanmıştır.

\subsubsection{Langmuir İzotermi}

$\mathrm{Bu}$ izoterm, adsorbent yüzeyinde adsorplayıc1 noktaların olduğunu farz eder. Her adsorplayıcı noktanın bir molekül adsorplayacağını kabul ederek oluşan tabakanın bir molekül kalınlığında bir tabaka olacağını söyler. Denge halinde maksimum adsorpsiyon kapasitesine ulaşıılmış ve yüzey tek tabakayla kaplanmış olur [27]. İzotermin matematiksel ifadesi Eşitlik 5'de verilmiştir.

$q_{e}=\frac{q_{\text {maks }} K_{L} C_{e}}{1+K_{L} C_{e}}$

$\mathrm{C}_{\mathrm{e}}$ : Adsorpsiyon sonrası çözeltide kalan maddenin konsantrasyonu $(\mathrm{mg} / \mathrm{L})$, 
$\mathrm{q}_{\mathrm{e}}$ : Birim adsorbent üzerine toplanan madde miktarı (mg/gr)

$\mathrm{K}_{\mathrm{L}}$ : İzoterm sabiti (L/mg),

$\mathrm{q}_{\text {maks }}$ : Adsorbentın maksimum adsorplama kapasitesi (mg/g).

Langmuir izotermi 0,947 korelasyon katsayısı ile NEK' in RB39 için maksimum adsorpsiyon kapasitesini ve $\mathrm{K}_{\mathrm{L}}$ değerini sırasıyla $432,12 \mathrm{mg} / \mathrm{g}$ ve $107,60 \mathrm{~L} / \mathrm{mg}$ olarak hesaplamıştır. Modelin tahmin ettiği maksimum adsorpsiyon kapasitesi, deneysel veri ile uyum içerisinde olsa da elde edilen 0,947 korelasyon katsayıs1 bu izotermin RB39'un NEK tarafindan distile sudan adsorpsiyonla giderim sürecini açıklamada orta derecede başarılı olduğunu göstermektedir.

\subsubsection{Freundlich İzotermi}

Freundlich, adsorpsiyon prosesini ifade eden ampirik bir denklem geliştirmiştir. Freundlich'e göre; bir adsorbentin yüzeyi üzerinde bulunan adsorpsiyon alanları heterojendir yani farklı türdeki adsorpsiyon alanlarından teşkil edilmiştir. [28]. Freundlich izoterminin matematiksel ifadesi Eşitlik 6'da verilmiştir.

$q_{e}=K_{F} C_{e}^{1 / n}$

$\mathrm{K}_{\mathrm{F}}$ : izoterm sabiti (L/mg), 1/n: Adsorpsiyon heterojenitesinin yoğunluğunu gösterir ve 0 ile 1 arasında değerler almaktadır (birimsiz).

Freundlich izotermi 0,993 korelasyon katsayısı ile adsorpsiyon sürecini Langmuir izotermine göre oldukça başarılı bir şekilde açıklamıştır. Freundlich izoterminin non-lineer olarak çözümlenmesiyle $K_{F}$ ve $n$ değerleri sirasıyla $117,50 \mathrm{~L} / \mathrm{mg}$ ve 0,368 olarak hesaplanmıştır. Hesaplanan $\mathrm{n}$ değeri, yüzey heterojenitesinin yoğun olduğunu göstermektedir.

\subsection{Maliyet Analizi}

Bir adsorbentin etkinliğinin araştırılmasında adsorpsiyon kapasitesi en önemli parametrelerden biridir. Ancak adsorpsiyon kapasitesinin yanında adsorbent maliyeti de oldukça önem arz etmektedir. Düşük maliyetli alternatif adsorbentlerin aritma performanslarının araştırıldığı çalışmalarda, adsorbentlerin maliyet analizlerine nadiren değinilmekledir. Oysa kullanılan adsorbentin maliyeti, endüstriyel ölçeklerde uygulanabilirliği açısından önem arz etmektedir. Bu çalışmada, kullanılan NEK'in basit bir maliyet analizi yapılmıştır. Eucalyptus camaldulensis kabukları dünya genelinde yenilenebilir ve oldukça yaygın bulunan bir karakterdedir. Buna ilaveten Euclayptus türleri kağıt hamuru ve kağıt üretim endüstrilerinde uygun fiber yapısından dolayı sıklıkla hammadde olarak tercih edilmektedir. Bu endüstrilerde kabuk sıyırma işlemleri sonucu bol miktarda kabuk elde edilmektedir [29]. Bu durumda Eucalyptus kabuklarının, düşük maliyetli adsorbent üretimi açısından önemli bir potansiyele sahip olduğu görülmektedir. Bir ton NEK'in üretimi için kullanılan hammadde, kimyasal madde ve elektrik enerjisi açısından yaklaşık 200 dolar maliyet hesaplanmıştır. Adsorpsiyon süreçlerinde yaygın bir adsorbent olarak kullanılan aktif karbonun 1 tonunun maliyeti, kalitesine bağlı olarak 700 ile 5000 dolar arasında değişmektedir [30]. Bu durumda NEK düşük maliyetli ve etkili bir adsorbent karakteri sergilemektedir.

\section{SONUCC}

$\mathrm{Bu}$ çalışmada, Eucalyptus camaldulensis kabuklarının yüzeyinin nano manyetit ile kaplanmasından elde edilen düşük maliyetli bir adsorbent ile RB39'un distile sudan ve sentetik atıksudan, değişen koşullar altında adsorpsiyonla giderimi araştırılmıştır. Elde edilen bulgular sentetik atıksudaki kirleticilerin, boyar madde giderimi sırasında, adsorbent yüzeyindeki adsorpsiyon sitlerini işgal ettiğini ve boyar madde için adsorbentin adsorpsiyon kapasitesini azalttığını göstermiştir. Yapılan çalışmalar, adsorpsiyon süreci üzerine $\mathrm{pH}$ 'ın, sıcaklığın, adsorbent dozunun ve başlangiç RB39 konsantrasyonunun önemli derecede etki ettiğini göstermiştir. Adsorpsiyon süreci için optimum sıcaklığın ve pH'ın sirasıyla $50^{\circ} \mathrm{C}$ ve 9 olduğu tespit edilmiştir. $300 \mathrm{mg} / \mathrm{L}$ RB39, $\mathrm{pH}$ 10'da, $50^{\circ} \mathrm{C}$ 'de ve 0,1 gram $\mathrm{NEK}$ ile distile sudan $\% 90,50$ 
verimle giderilirken aynı şartlar altında sentetik atıksudan \%78,10 verimle giderilmiştir. Distile su için optimum şartlar altında $300 \mathrm{mg} / \mathrm{L}$ RB39 için 0,1 gram NEK kullanılarak 407,10 $\mathrm{mg} / \mathrm{g}$ adsorpsiyon kapasitesi elde edilmiştir. Freundlich izotermi adsorpsiyon sürecini 0,993 korelasyon katsayısı ile başarılı bir şekilde açıklamıştır. Termodinamik parametreler, adsorpsiyon sürecinin endotermik reaksiyonlar ile gerçekleştiğini göstermiştir. Çalışmadan elde edilen sonuçlar, NEK'in, RB39'un atıksudan adsorpsiyon ile giderilmesinde başarı ile kullanılabilecek bir adsorbent olduğunu göstermiştir.

\section{KAYNAKLAR}

1. Senthilkumaar, S., Kalaamani, P., Porkodi, K., Varadarajan P.R., Subburaam, C.V., 2006. Adsorption of Dissolved Reactive Red Dye from Aqueous Phase onto Activated Carbon Prepared from Agricultural Waste, Bioresource Technology, 97(14), 1618-1622.

2. Ahmad, M.A., Alrozi, R., 2011. Optimization of Rambutan Peel Based Activated Carbon Preparation Conditions for Remazol Brilliant Blue Removal, Chemical Engineering Journal, 168(1), 280-85.

3. Ip, A.W.M., Barford, J.P., McKay, G., 2009. Reactive Black Dye Adsorption/desorption onto Different Adsorbents: Effect of Salt, Surface Chemistry, Pore Size and Surface Area, Journal of Colloid and Interface Science, 337(1), 32-38.

4. Walker, G.M., Weatherley, L.R., 1997. Adsorption of Acid Dyes onto Granular Activated Carbon in Fixed Beds, Water Research, 31(8), 2093-101.

5. Ngomsik, A.F., Bee, A., Draye, M., Cote, G., Cabuil V., 2005. Magnetic NanoMicroparticles for Metal Removal and Environmental Applications: a Review, C. R. Chimie, 8, 963-970.

6. Kaminski, M.D., Nunez, L., 1999. ExtractantCoated Magnetic Particles for Cobalt and Nickel Recovery from Acidic Solution, J. Mag. Mat., 194, 31-36.

7. Nethaji, S., Sivasamy, A., Mandal, A.B., 2013. Preparation and Characterization of Corn $\mathrm{Cob}$
Activated Carbon Coated with Nano-Sized Magnetite Particles for the Removal of Cr (VI), Bioresource Technology, 134, 94-100.

8. Malik, P.K., 2003. Use of Activated Carbons Prepared from Saw Dust and Rice-Husk for Adsorption of Acid Dyes: a Case Study of Acid Yellow 36, Dyes and Pigments, 56, 239-249.

9. Nevine, K.A., 2008. Removal of Reactive Dye from Aqueous Solutions by Adsorption onto Activated Carbons Prepared from Sugarcane Bagasse Pith, Desalination, 223, 152-161.

10. Suhong, C., Jian, Z., Chenglu, Z., Qinyan, Y., Yan, L., Chao, L., 2010. Equilibrium and Kinetic Studies of Methylorange and Methylviolet Adsorption on Activated Carbon Derived from Phragmitesaustralis, Desalination, 252, 149-156.

11. Taimur, K., Shamsul, R.M.K., Malay, C., 2010. Adsorptive Removal of Reactive Yellow 15 from Aqueous Solution by Coconut Coir Activated Carbon, Adsorption Science and Technology, 28 (7), 657-667.

12. Wang, L., 2012. Application of Activated Carbon Derived from 'Waste' Bamboo Culms for the Adsorption of Azo Disperse Dye: Kinetic, Equilibrium and thermodynamic Studies, Journal of Environmental Management, 102, 79-82.

13. Mohammad, R.S., Mahdi, H., Gordon, M., 2014. Breakthrough Curve Analysis for Fixedbed Adsorption of azo Dyes Using Novel Pine Cone-Derived Active Carbon, Adsorption Science and Technology 32 (10), 791-806.

14. Kouassi, N.A., Yao, A.Y., Kouassi, B.Y., Droh, L.G., Albert, T., 2015. Investigation of Dye Adsorption onto Activated Carbon from the Shells of Macoré Fruit, Journal of Environmental Management, 156, 10-14.

15. Gabriela, G.S., Selene, M.A., Guelli, U.S., Debora, O., Antonio, A.U.S., 2016. The Application of Textile Sludge Adsorbents for the Removal of Reactive Red 2 Dye, Journal of Environmental Management, 168, 149-156.

16. Ipek, G., Gulerman, A.S., Filiz, B.D., 2006. Importance of $\mathrm{H}_{2} \mathrm{O}_{2} / \mathrm{Fe}^{2+}$ Ratio in Fenton's Treatment of a Carpet Dyeing Wastewater, Journal of Hazardous Materials, 136, 763-769.

17. Ilda, V., Yasemin, K.A., Unal, S.E., Zeren, B. G., Coskun, A., 2012. Techno-Economic 
Analysis of Textile Dye Bath Wastewater Treatment by Integrated Membrane Processes under the Zero Liquid Discharge Approach. Resources, Conservation and Recycling, 58, 25-35.

18. Aksu, A., Sag, Y., Nourbakhsh, M., Kutsal, T., 1993. Atıksulardaki Bakır, Krom Ve Kurşun İyonlarının Çeşitli Mikroorganizmalarla Adsorplanarak Giderilmesinin Karşılaştırmalı Olarak İncelenmesi, Turkish Journal of Engineering \& Environmental Sciences, 19, 285-293.

19. Guptaa, S.S, Krishna, G.B., 2011. Kinetics of Adsorption of Metal Ions on Inorganic Materials: A Review, Advances in Colloid and Interface Science, 162(1-2), 39-58.

20. Behzad, H., Susana, R.C., Mohammad, A.A., Mohammad, A., Inderjee, T.T., Shilpi, A., Vinod, K. G., 2015. Kinetics and Thermodynamics of Enhanced Adsorption of the Dye AR18 using Activated Carbons Prepared from Walnut and Poplar Woods, J. Mol. Liq., 208, 99-105.

21. Senthilkumaar, S., Varadarajan, P.R., Porkodi, K., Subbhuraam, C.V., 2005. Adsorption of Methylene Blue onto Jute Fiber Carbon: Kinetics and Equilibrium Studies, J. Coll. Int. Sci., 284, 78-82.

22. Almeida, C.A.P., Debacher, N.A., Downs, A.J., Cottet, L., Mello, C.A.D., 2009. Removal of Methylene Blue from Colored Effluents by Adsorption on Montmorillonite Clay, Journal of Colloid and Int. Sci., 332, 46-53.

23. Arias, F., Sen, T.K., 2009. Removal of Zinc Metal Ion $\left(\mathrm{Zn}^{2+}\right)$ from Its Aqueous Solution by Kaolin Clay Mineral: a Kinetic and Equilibrium Study, Colloids and Surfaces 348, 100-108.

24. Upendra, K., 2011. Thermodynamics of the Adsorption of Cd (II) from Aqueous Solution on NCRH, International Journal of Environmental Science and Development, 2, 334-336.

25. Sara, D., Tushar, K.S., 2012. Removal of Anionic Dye Congo Red from Aqueous Solution by Raw Pine and Acid-Treated Pine Cone Powder as Adsorbent: Equilibrium, Thermodynamic, Kinetics, Mechanism and
Process Design, Water Research, 46, 1933-1946.

26. Allen, S.J., Mckay, G., Porter, J.F., 2004. Adsorption Isotherm Models for Basic Dye Adsorption by Peat in Single and Binary Component Systems, Journal of Colloid and Interface Science, 280(2), 322-333.

27. Benefield, L.D., Judkins, J.F., Weand, B.L., 1982. Process Chemistry for Water and Wastewater Treatment, Prentice-Hall, Inc, Englewood Cliffs, New Jersey.

28. Chiou, M.S., Li, H.Y., 2002. Equilibrium and Kinetic Modeling of Adsorption of Reactive Dye on Cross-linked Chitosan Beads, Journal of Hazardous Materials, 93(2), 233-24.

29. Marilia, P., Doahn, F., Vicelina, B.S., 2014. Evaluation on Paper Making Potential of Nine Eucalyptus Species Based on Wood Anatomical Features, Industrial Crops and Products 54, 327-334.

30. Saygili, H., Guzel, F., Onal, Y., 2015. Conversion of Grape Industrial Processing Waste to Activated Carbon Sorbent and it's Performance in Cationic and Anionic Dyes Adsorption, Journal of Cleaner Production, 93, 84-93. 
